\title{
A CRISE DO TRABALHO DOCENTE NO SOCIEDADE DO TRABALHO
}

\section{THE CRISIS OF TEACHING WORK WITHIN THE CRISIS OF THE SOCIETY OF WORK}

\author{
Eduardo Donizeti Girotto ${ }^{1}$ \\ Najla Mehanna Mormul²
}

\section{RESUMO}

O presente trabalho, efeito de pesquisas realizadas em escolas públicas na região metropolitana de São Paulo, busca analisar a crise do trabalho relacionando-a com uma crise mais ampla e que envolve a sociedade moderna, totalizada pelo modo de produção capitalista. Esta sociedade assenta suas bases e fundamentos em uma noção de trabalho que, ao contrário de dar identidade e significado para as práticas sócio-espaciais de homens e mulheres espalhados por diversos territórios do mundo, tem como único objetivo reproduzir um modo de produção pautado na mercadoria. Este trabalho abstrato, produtor de alienação, visa totalizar todas as formas de produção. Com o crescente processo de proletarização do professor, verificado pela retração das condições de realização de seu trabalho ao mínimo necessário, o trabalho abstrato passa também a totalizar as atividades docentes. Com isso, de construtor de reflexões e questionamentos sobre a sociedade, o professor passa a se inserir nesta lógica como apenas mais um trabalhador alienado pela reprodução de um trabalho abstrato que só tem sentido no interior do modo de produção de mercadorias.

PALAVRAS-CHAVE: Trabalho docente - Capital - Ação - Política - Trabalho Abstrato 


\section{ABSTRACT}

The present work, effect of research conducted in public schools in the metropolitan region of Sao Paulo, analyzed the crisis of work relating it to a broader crisis that involves the modern society, totalized by the capitalist mode of production. This society builds its bases and foundations on a notion of work that, unlike of give identity and meaning to the socio-spatial practices of men and women scattered in different territories of the world, has the sole purpose of playing a mode of production founded on the commodity. This abstract work, producer of alienation, aims to totalize all forms of production. With the growing process of impoverishment of the teacher, verified by the retraction of the conditions for their work to a minimum, the abstract work is also to totalize the teacher's works. With this, builder of reflections on society, the teacher moves to fill this logic as just another alienated worker for the reproduction of an abstract work that has meaning only within the mode of production of goods.

KEYWORDS: Teacher's work - Capital - Action - Politics - Abstract work

\section{INTRODUÇÃO: DO TRABALHO AO TRABALHO ABSTRATO}

Uma das questões essenciais que tem marcado o debate de diferentes correntes no interior do pensamento marxista diz respeito a chamada ontologia do trabalho. Nesta discussão, a problemática envolve o significado do trabalho enquanto categoria de interpretação da sociedade capitalista. Os defensores da chamada ontologia do trabalho alegam ser esta uma categoria transitórica fundadora da condição humana. Para tais autores, seria o trabalho um dos processos responsáveis pela humanização dos seres humanos e para sua constituição enquanto seres sociais. É por meio do trabalho que o homem se apropria do meio, sendo que esta relação a cada ação desencadeada pelos homens no sentido de "dominar" as forças naturais há uma mútua modificação. Ao transformar o meio a partir do trabalho, os homens se modificam objetiva e subjetivamente.

Para legitimarem sua argumentação, os autores desta ontologia do trabalho partem de trechos das obras de Marx. Em alguns trechos de "O 
Capital", como o que citamos logo a seguir, esta noção está posta.

\begin{abstract}
Antes de tudo, o trabalho é um processo do que participam o homem e a natureza, processo em que o ser humano com sua própria ação, impulsiona, regula e controla seu intercâmbio material com a natureza. Defronta-se com a natureza como uma de suas forças. Põe em movimento as forças naturais de seu corpo, braços, e pernas, cabeça e mãos, a fim de apropriar-se dos recursos da natureza, imprimindo-Ihes forma útil a vida humana. Atuando assim sobre a natureza externa e modificando-a, ao mesmo tempo modifica sua própria natureza. Desenvolve as potencialidades nela adormecidas e submete ao seu domínio o jogo das forças naturais (MARX, 1984, p. 202).
\end{abstract}

Há, porém, uma certa vertente no interior do pensamento marxista que discorda desta leitura acerca da ontologia do trabalho. Para autores como Paul Lafargue e, mais recentemente, Robert Kurz, a categoria trabalho só tem sentido no interior do modo de produção capitalista. Segundo o Robert Kurz, esta sociedade surgida do desenvolvimento do modo de produção capitalista e do consequente advento da modernidade, para além das muitas designações cunhadas para defini-la (sociedade do consumo sociedade da informação, entre outros) deve, antes, ser denominada de "Sociedade do Trabalho". Esta denominação se justifica no sentido em que o trabalho aparece, nesta sociedade, como mediador positivo das relações sociais, perpassando as práticas e os discursos científicos e ideológicos em diferentes momentos e situações.

Em sua forma especificamente histórica, o trabalho nada mais é do que a exploração econômica abstrata, em empresas, da força de trabalho humana e das matérias-primas. Nesse sentido ele pertence exclusivamente à era moderna, e como tal foi acolhido acriticamente por ambos os sistemas conflitantes do pós-guerra. Esse trabalho, nessa curiosa forma abstrata, pode ser definido também como atividade que, de maneira igualmente curiosa, traz sua finalidade em si mesma. (KURZ, 1999, p. 18)

Como podemos perceber neste trecho, o trabalho, segundo o autor, não é, de forma alguma, supra-histórico. Enquanto categoria explicativa da sociedade atual, ele surge como fundamento do modo de produção capitalista e da sociedade moderna dele advinda e só tem sentido enquanto categoria no interior desta sociedade. Não há, portanto, uma categoria trabalho atemporal, transistórica, ontologizada, como fundamento do homem e de sua formação 
enquanto ser social. Ao contrário, trata-se de um trabalho situado e localizado no interior destes processos, trabalho abstrato que tem como único objetivo reproduzir as contradições sociais ligadas ao modo de produção capitalista em sua totalização da sociedade.

Segundo Kurz, em outras formas de organizações sociais anteriores ao capitalismo - ou sistema mundial reprodutor de mercadorias como define o autor - a categoria trabalho não está presente. Contrapostas ao trabalho, categoria moderna como vimos, outras formas de atividades responsáveis pela mediação entre homem e meio, produziram outras maneiras objetivas e subjetivas de reproduzir a vida social, no que diz respeito às necessidades de sobrevivência biológica e social dos homens reunidos em comunidades. Com o advento do trabalho abstrato, a reprodução da sociedade está para além das necessidades reais da reprodução do homem enquanto ser biológico. Se o trabalho aparece, nesta sociedade, como o gasto de energia necessário para que os homens se reproduzam enquanto seres sociais e biológicos, ele é antes mediação necessária para que a lógica do sistema mundial produtor de mercadorias se realize. Apesar de sua aparência positiva, o trabalho abstrato, oculta a negatividade da alienação do homem em relação ao meio e as suas reais condições de reprodução social, em favor da reprodução de toda a sociedade que, neste caso, nada mais é do que a reprodução ampliada do sistema mundial produtor de mercadorias. Dessa maneira, a reprodução da sociedade do trabalho como elemento tautológico, com um fim em si mesmo, é o objetivo único que põe sobre a categoria trabalho a centralidade no interior do modo de produção capitalista, mesmo que a reprodução geral da sociedade apareça como reprodução isolada.

Ao analisar a crise do socialismo real, Robert Kurz aponta para o fato de que o mesmo deve ser entendido como um momento da reprodução ampliada do modo de produção capitalista e não como alternativa provável de enfrentamento, de revolução social contrária ao desenvolvimento do capitalismo. Para fundamentar seu argumento e sua crítica, o autor constrói uma análise que busca desvendar os pressupostos e fundamentos comuns existentes entre os dois sistemas econômicos e sociais, entre o socialismo real e o modo de produção capitalista. Entre os elementos comuns, o autor destaca a similaridade como os dos sistemas concebem a categoria trabalho, vista 
como positiva e ontológica. A exploração do trabalho enquanto fundamento destes dois sistemas e a crise verificada nos mesmos decorrentes das contradições relacionadas à sociedade do trabalho são, portanto, elementos que permitem uma análise para além da perspectiva dual do enfrentamento entre socialismo e capitalismo, possibilitando assim uma leitura que parta do pressuposto do socialismo real enquanto momento da reprodução ampliada do modo de produção capitalista.

Porém, já no início final do século XIX Paul Lafargue apontava para aquilo que ele considerava como uma miopia do movimento proletariado, que seja, uma certa apologia do trabalho como redentor da humanidade. Segundo o autor,

Uma estranha loucura está a apossar-se das classes operárias das nações onde reina a civilização capitalista. Esta loucura arrasta atrase de si misérias individuais e sociais que, há dois séculos, atormentam a triste humanidade. Esta loucura consiste no amor ao trabalho, na paixão moribunda pelo trabalho, levada ao depauperamento das forças vitais do indivíduo e da sua prole. Em vez de reagirem contra esta aberração mental, os padres, os economistas e os moralistas sacrossantificam o trabalho." (LAFARGUE, 1977, p.11)

A ontologia do trabalho como elemento fundamental da humanidade pretende-se enquanto explicação racional capaz de dar sentido a chamada alienação do capital que se torna, por sua vez, alienação do trabalho. Segundo Lafargue, ao lutar a favor do trabalho e não contra a estrutura social na qual ele é um dos princípios fundamentais, os trabalhadores reproduzem as próprias condições de sua alienação, no sentido em que perdem de vista o fato de que esta sociedade reproduz-se criticamente a partir do trabalho abstrato. A afirmação do trabalho enquanto fundamento ontológico da humanidade, enquanto categorial atemporal oculta o fato de que só nesta organização social as relações sociais são totalizadas pelo trabalho. Neste sentido, o trabalho abstrato, desde o seu início, é anti-humano, porque limita as potencialidades dos homens àquelas definidas anteriormente pelo capital.

Em outra perspectiva, Hannah Arendt, em seu livro "A condição Humana" busca compreender os fundamentos da própria humanidade, mesmo que limitada as experiências dos atenienses no período clássico da Grécia Antiga. Em sua análise, o trabalho surge como um dos elementos - e não 
como o principal - na definição das relações dos homens entre si e com o meio. Para a autora, o trabalho humano seria o responsável pela sensação aparente de durabilidade frente a instabilidade da condição humana. Seria, portanto, a marca dos homens que, em certa medida, Ihes garantiria a permanência mesmo após a vida biológica ter se findado. Vale ressaltar que para a autora o trabalho não constitui em elemento central da vida humana, mas divide lugar com o labor e a ação enquanto elementos marcantes da condição humana. Enquanto o labor pode ser entendido como a energia vital necessária para que o homem reproduza sua condição de ser vivo, o trabalho e a ação seriam os elementos fundamentais para a realização do homem enquanto ser social. A partir do trabalho, o homem se relaciona com o meio e o transforma materialmente, criando uma certa aparência de durabilidade de sua condição instável. Já na ação, é a partir da palavra, do discurso e de suas práticas políticas que esta sensação de durabilidade é construída. Apenas na e pela ação que o homem se constitui enquanto ser político.

É com palavras e atos que nos inserimos no mundo humano; e esta inserção é como um segundo nascimento, no qual confirmamos e assumimos o fato original e singular do nosso aparecimento físico original. Não nos é imposto pela necessidade, como o labor, nem se rege pela utilidade, como o trabalho. Pode ser estimulada, mas nunca condicionada pela presença dos outros em cuja companhia desejamos estar; seu ímpeto decorre do começo que vem ao mundo quando nascemos, e ao qual respondemos começando algo novo por nossa própria iniciativa. Agir, no sentido mais geral do termo, significa tomar iniciativa, iniciar (como indica a palavra grega archein, começar, ser o primeiro e, em alguns casos, governar), imprimir movimento a alguma coisa (que é o significado original do termo latino agere). (ARENDT, 2008, pags. 189-190)

É, portanto, a partir da ação que o homem nasce para o mundo, constitui-se enquanto ser político, em relação constante com os outros homens e com o meio. Esta afirmação humana, como aponta Arendt, não se constituiu enquanto necessidade, mas é resultado da própria escolha, da sua capacidade de decidir e de iniciar algo novo.

Com o advento da modernidade, porém, há uma inversão destas relações entre labor, trabalho e ação que Arendt identifica como elemento central no processo de alienação humana. Segundo a autora, o trabalho que tinha como única utilidade criar a sensação de permanência da condição 
instável da humanidade se impõe como condição necessária para que o próprio trabalho abstrato, base do desenvolvimento do modo de produção capitalista, crie as condições para que uma nova forma de relação entre os homens e o meio surja. Retornado a KURZ, é este trabalho que se torna a base da reprodução social da mercadoria. Para o autor,

\begin{abstract}
A forma de reprodução social da mercadoria torna-se uma segunda natureza, cuja necessidade apresenta-se aos indivíduos igualmente insensível e exigente como o da primeira natureza, apesar de sua origem social. (KURZ,1999, p. 21)
\end{abstract}

Neste sentido, numa tentativa de diálogo entre Arendt e Kurz vemos que, com o advento do trabalho abstrato a partir do desenvolvimento do modo de produção capitalista, o labor, primeira natureza porque necessária a reprodução básica do homem enquanto ser biológico, só pode se realizar a partir da inserção do indivíduo nos termos da sociedade do trabalho, totalizada pelo trabalho abstrato. Apesar de surgir para o indivíduo como necessidade natural, este trabalho e as relações dele resultantes são antes condição social de reprodução do modo de produção capitalista, sendo, portanto, necessário não a reprodução dos homens, mas a reprodução desta sociedade como um fim em simesmo.

Totalizada, desta forma, pelo trabalho abstrato, a vida humana não pode ser realizar enquanto ação nos princípios definidos por Arendt. A ação, neste sentido, se realiza enquanto simulação, enquanto sensação de se agir consciente sem o saber que assim o faz em favor da própria reprodução do modo de produção capitalista. É, portanto, o caminho da desumanização no sentido em que o nascimento social dos homens já não mais se realiza.

A análise desta problemática aponta-nos, portanto, uma necessidade cada vez maior de se produzir uma crítica social e científica que tenha como objeto as categorias que dizem respeito ao modo de produção capitalista. De outra forma, se assim não procedermos, corremos o risco de produzir uma crítica que se constitui antes como apologia do modo de produção capitalista. Esta análise se torna ainda mais necessária quando a crise da chamada sociedade do trabalho se aprofunda, apontando assim seus limites e deixando escapar possibilidade de superação - não da crise, mas da sociedade e de 
seus fundamentos.

\section{A CRISE DO TRABALHO DOCENTE}

Voltemos agora para a realidade encontrada nas escolas estudadas durante o desenvolvimento da pesquisa. Como forma de interpretação dos relatos obtidos em nossos trabalhos de campo naquela unidade escolar, nos propomos aqui pensar a crise do trabalho docente ali verificado enquanto momento da crise da sociedade do trabalho. A crise da sociedade do trabalho surge no momento inicial da sua formação. Põe e se repõem conforme aprofunda sua reprodução e assim suas contradições internas. Apesar de aparecer como solução da crise, a expansão do modo de produção capitalista aprofunda-a no sentido em que aprofunda também suas contradições fundamentais. No caso da análise da crise do trabalho docente enquanto momento da crise da sociedade do trabalho, algumas dificuldades são encontradas, principalmente no que diz respeito a se estabelecer uma relação entre um momento particular e o desenvolvimento geral da categoria trabalho no interior da sociedade do trabalho.

A análise crítica do trabalho docente enquanto trabalho abstrato passa ao largo de diversas análises que propõem compreender a problemática dos professores em suas práticas cotidianas. O que temos visto é que muitas destas análises, ao centrar demais o olhar sobre a profissão docente enquanto trabalho diferente dos demais, isola o professor do restante da sociedade, como se a relação aluno-professor-escola pudesse ser pensada para além da análise de toda a sociedade. Nosso pressuposto teórico parte da seguinte afirmação: a crise do trabalho docente, que ora verificamos, é um momento da crise da sociedade do trabalho que apresenta suas particularidades e problemáticas próprias que precisam ser desvendadas para que a crise geral possa também ser melhor compreendida.

Para tanto, porém, faz-se necessário considerarmos que ao tratarmos da sociedade do trabalho o fazemos a partir de certa situação geográfica, que seja, um olhar situado na periferia dos processos ligados a lógica de reprodução do sistema mundial produtor de mercadorias. Falamos, portanto, de uma sociedade do trabalho que não se formou enquanto trabalho 
para todos, principalmente porque nossa acumulação primitiva não ocorreu nos moldes descritos por Marx. Ao mesmo tempo em que uma grande parcela da população no Brasil tem sido expropriada dos seus meios de produção, esta mesma parcela não se forma enquanto mão-de-obra assalariada, enquanto elemento vivo do trabalho abstrato. Vivemos, portanto, a perspectiva de uma sociedade do trabalho que se realiza enquanto sociedade do não-trabalho, o que contribui, em certa medida, para reafirmar a positividade do trabalho enquanto aparência. Nesta perspectiva, o problema não está no trabalho abstrato, mas em sua falta. E as lutas sociais que, em aparência e discurso, se põem como críticas contribuem para a reprodução ampliada do modo de produção capitalista, ao defenderem o trabalho enquanto fundamento ontológico da humanidade.

Neste sentido, nossa análise parte da compreensão do trabalho docente dos professores em escolas na periferia da cidade de São Paulo. Esta observação faz-se necessária no sentido em que, na periferia, esta crise da sociedade do trabalho, que aqui parcialmente se formou, pode ser verificada mais claramente. Na periferia, encontramos a sociedade do trabalho ainda enquanto projeto, ao mesmo tempo em que já se põe como tragédia. E cabe a escola, pelo menos em discurso, realizar certas ações que permitam manter as aparências, ocultando a tragédia a partir da falsa produção do projeto. À escola, em grande medida, cabe realizar a continuidade da acumulação primitiva, formando ideologicamente a mão-de-obra a partir da apologia do trabalho enquanto único elemento redentor de toda a humanidade. Cabe, portanto, a escola, a partir da apologia do trabalho ocultar as contradições da sociedade do trabalho que se realize na atualidade enquanto negação do trabalho.

A partir disso, qual o papel que tem desempenhado o trabalho docente neste contexto? O discurso do trabalho docente tenta dar significado aquilo que, no interior do modo de produção capitalista não tem sentido para além do capital, que seja, o trabalho abstrato. Ao produzir, pelo menos em aparência, mão-de-obra para este trabalho, o faz sem que sejam desvendadas as contradições presentes no seu próprio interior e que são, enfim, contradições de toda a sociedade. Ao se esvaziar da crítica à sociedade do trabalho, o trabalho docente se reafirma enquanto trabalho abstrato, porque 
medido em horas-aulas, porque igual e quantificado em relação a qualquer outro trabalho. Isto talvez explique a utilização cada vez maior de termos econômicos e administrativos para avaliar o "desempenho" - e aqui está um deles - dos alunos e professores: produtividade, rendimento, etc.. A adoção da linguagem econômica e administrativa no interior do processo educativo é uma das marcas de uma sociedade dominada pelo trabalho abstrato. Para além da crítica, o que temos visto é a adequação à linguagem e aos lugares comuns que marcam esta sociedade e que ocultam suas contradições.

Da mesma forma, a adoção de currículos únicos, da centralização daquilo que deve ser ensinado, da negação do lugar como realidade a ser analisada, discutida, conhecida também são elementos que revelam a relação do trabalho docente com a manutenção das aparências em uma sociedade em crise. A aparente preocupação social de determinadas ações no sentido de centralização curricular que parecem significar anseios de toda a sociedade, ocultam os interesses únicos da sociedade do trabalho. A apologia do trabalho precisa se formar enquanto verdade transistórica e trans-espacial. Precisa ser verdade em São Paulo e em Recife. Precisa unir os trabalhadores em favor do trabalho e não contrários a ele. Para tanto, cabe também a escola realizar este discurso. Uma rápida olhada pelos livros didáticos espalhados pelo país e logo constataremos a força do discurso da sociedade do trabalho que rapidamente se espalha, criando assim a aparência de amálgama social em uma sociedade em ruptura.

Por sua vez, quando inerte e paralisante, o trabalho docente é também trabalho abstrato como outro qualquer, vazio de significados, repleto de contradições não desvendadas porque para isto não se propõe. Em certa medida, isso explica o cansaço, as faltas excessivas, o desânimo que temos encontrado nos corredores das escolas estudadas, cansaço diário de uma rotina que tem no pagamento do final do mês, muitas vezes, seu único significado. Nestes corredores também está presente certa nostalgia, uma romantização, a idealização de um passado que muitas vezes não existiu. Fala-se de melhores condições de trabalho, de perspectivas, de salários mais elevados, de um "momento onde o trabalho docente tinha significado". Não há, porém, a crítica à sociedade do trabalho, nem ao trabalho abstrato como seu fundamento. O que há, ao contrário, é uma reafirmação do mesmo quando 
ainda Ihe era possível esconder parte de sua abstração porque a aparência de elevação social assim o permitia. Este ocultamento era possível também porque a acumulação de capital e sua reprodução "inseriam" os alunos recémsaídos daquelas salas de aula. À realização da acumulação primitiva, da formação da mão-de-obra assalariada acompanhava um processo de ascensão social pelo trabalho, isto porque, assim como o trabalho, a escola era também para poucos. Apenas alguns se formavam como trabalho assalariado, enquanto uma massa gigantesca encontrava-se fora da escola, marginalmente a sociedade do trabalho. Havia perspectiva de futuro, mesmo que em aparência, mesmo que só para alguns. Por causa disso, desta perspectiva de futuro, ainda era possível controlar a periferia. $O$ autocontrole estava presente como ação necessária, pelo menos em aparência, para a garantia de futuro.

Com o aprofundamento da crise da sociedade do trabalho, já não há mais esta perspectiva. A sociedade do trabalho, em sua crise mundial, se realiza enquanto negação do trabalho nas periferias. Gerações se reproduzem as margens desta sociedade e também no seu interior. A democratização do acesso a educação significou acesso ao discurso da sociedade do trabalho e a não inserção de fato na mesma enquanto trabalhador assalariado. Há agora excesso de trabalhadores formados em uma sociedade na qual o trabalho é cada vez menos necessário. Estas gerações, expropriadas da sociedade do trabalho porque nem mais constituídas enquanto reserva de mão-de-obra assalariada já não encontram sentindo no discurso do trabalho reproduzido no interior da escola. Encontram-se, ao mesmo tempo, entre uma certa contestação e o fatalismo, encontrado em frases como "mas sempre foi assim!". Como alunos, aprenderam a jogar a jogo, entenderam as regras da dissimulação presente na escola. Já pensam numa reprodução com o mínimo de trabalho, sem, porém, negar o capital e sua lógica. A expansão do tráfico de drogas e do domínio que exerce sobre a reprodução da vida social nas periferias é uma das marcas deste contexto.

\section{CONSIDERAÇÕES FINAIS: DO TRABALHO ABSTRATO À AÇÃO DOCENTE}

E são todas estas contradições que explodem nos corredores da 
escola, que hoje se deixam aparecer e permeiam as relações sociais entre os diferentes sujeitos da educação. A violência, tantas vezes discutida e analisada, é um momento do aprofundamento da crise da sociedade do trabalho que tem negado a uma grande quantidade de pessoas a possibilidade de realização da própria vida, enquanto elemento biológico. Porém, a esta crise que ganha força na escola e ali se deixa transparecer não se tem acompanhado um processo de análise e interpretação crítica da mesma. Em vão, professores tentam se proteger. Em vão, muros são erguidos, vigias contratados, disciplina requerida. A crise social, que ora verificamos, não é crise da escola e nem daqueles que a compõem. É crise da sociedade do trabalho, crise que expõe os limites da reprodução desta sociedade e que encontra na periferia suas mais profundas marcas. Para além da revolução, a resposta dada nas periferias vem por meio da violência generalizada, do avanço do tráfico, da banalização da vida, da fetichização da técnica. O grito não é contra o capital como querem nos fazer crer algumas letras de RAP ${ }^{1}$, mas a favor da mercadoria, dos fetiches que sustentam a sua reprodução. É crise a favor da sociedade do trabalho, mesmo que esta já não seja mais possível. Crise que desvenda, por sua vez, a distância entre a crítica social e as práticas que por ora se realizam em pseudotentativas de enfrentamento.

O silêncio dos professores frente a tudo isso é marca de que a sociedade do trabalho nada deixa escapar. É a marca da ação transformada em simulação. Em nossa perspectiva, porém, a escola não pode ser pensada enquanto lugar do trabalho. É, antes, lugar da ação, do nascimento político dos homens, como nos aponta Arendt. É pela, escola, que os alunos podem iniciar algo novo, inserir-se criticamente num mundo posto, que de forma alguma são obrigados a aceitar. E é esta a escolha que, em certa medida, deveria caber aos professores. Escolha que é antes ação. Ação que é nascimento político e social, reinvenção, mesmo que insuficiente, mas necessária, da ordem das relações entre os homens e a sociedade.

Para tanto, a questão não está em controlar ou não a crise, mas em interpretá-la a partir de uma análise mais ampla da relação com toda a sociedade do trabalho, em buscar, no diálogo criativo com os diferentes

Do inglês, 'rhythm and poesy'; na tradução, "ritmo e poesia". 
sujeitos da educação, caminhos para superação da sociedade do trabalho. Como docente, cabe decidir a forma de encará-la, buscando nos limites de minha própria prática, as possibilidades da crítica a ser construída. Para além de um discurso reprodutor das contradições relacionadas ao capital, faz-se necessário que se possibilite a um número cada vez maior de pessoas uma compreensão categorial da crise para que a aparência de solução não seja tomada por solução. A partir de práticas cotidianas, cabem aos docentes a construção de momentos e movimentos, no interior do processo educativo, que permitam o desenvolvimento desta crítica categorial, desta análise que destitua a positividade do trabalho e abra outras possibilidades de enfrentamento da crise que não tomem as contradições solução da crise. Só assim, talvez, a ação docente possa se destituir de seu caráter de trabalho, de abstração fundamental a reprodução desta sociedade.

Para além de um mero movimento de profissionalização docente, necessário, mas insuficiente, o que propomos é ação docente, pedagógica, crítica e criativa que, situada, relacione toda sociedade na compreensão de sua crise e das ações necessárias para sua superação. Ação pedagógica que rompa com a subordinação da crítica que vem da Universidade como discurso e que oculta o fato de que a crítica social ainda é campo para alguns. Só há sentido na crítica quando feita de forma a ampliar a ação e o diálogo, quando feita em conjunto, coletivamente e quando tem na perspectiva da crítica categorial seus fundamentos. Pensar a ação docente para além do trabalho docente é, portanto, pensar as possibilidades na construção desta crítica a partir da base, das periferias, da derrubadas dos muros da escola e da exposição da crise profunda da sociedade do trabalho na qual somos todos agentes-objetos.

O que fica, portanto, desta experiência de campo em diferentes escolas na periferia paulista é a compreensão de que ali a escola é também reveladora dos limites do desenvolvimento do modo de produção capitalista no sentido em que coloca em relação, em movimento, contradições fundamentais que ele mesmo produz. Unificados pela lógica do trabalho abstrato, trabalho em negação, professores e alunos, de formas diferenciadas buscam dialogar acerca de tais perspectivas, sendo que muitas vezes, a partir de leituras e práticas particulares demais, o diálogo não se constitui dando lugar ao conflito, 
ao enfrentamento. Faz-se necessário, portanto, que se desenvolva uma leitura mais ampla das problemáticas encontradas nas múltiplas escolas da periferia paulista para que as mesmas não sejam enfrentadas apenas como questões pontuais ou relacionadas a fase de desenvolvimento psicológico dos alunos. Para além destas perspectivas, é preciso compreender a relação inerente entre escola, lugar e poder, em uma análise que busque, nas inter-relações entre escalas geográficas de realização do modo de produção capitalista os pontos de contatos existentes e as possibilidades de construção de uma sociedade mais justa, igualitária e fraterna.

\section{REFERÊNCIAS BIBLIOGRÁFICAS}

ARENDT, Hannah. O que é política?2. ed., Rio de Janeiro: Bertrand Brasil, 1999.

. A condição humana. 9. ed. São Paulo: Forense Universitária,1999.

. Entre o passado e o Futuro. São Paulo: Perspectiva, 2000.

KURZ, Robert. O Colapso da Modernização. 5. ed., São Paulo: Paz e

Terra, 1999.

LAFARGUE, Paul. O direito à preguiça. Lisboa: Teorema, 1977.

MARX, K. O Capital. O processo de produção do capital. v.1, 9. ed. São Paulo: Difícil, 1984.

1: Eduardo Donizeti Girotto: Mestre em Geografia Humana pela Universidade de São Paulo, Professor Assistente da Universidade Estadual do Oeste do Paraná - Campus Francisco Beltrão, Colegiado de Geografia. Email: egirotto@usp.br

2: Najla Mehanna Mormul: Mestre em Educação pela Universidade de Maringá, Professora Assistente da Universidade Estadual do Oeste do Paraná - Campus Francisco Beltrão, Colegiado de Geografia. Email: hinidmormul@gmail.com 